\title{
Optics outreach in Irish context
}

\section{Emer McHugh, Arlene Smith}

Emer McHugh, Arlene Smith, "Optics outreach in Irish context," Proc. SPIE 9666, 11th Education and Training in Optics and Photonics Conference, 96660C (5 June 2009); doi: 10.1117/12.2208026

Event: Eleventh International Topical Meeting on Education and Training in SPIE. Optics and Photonics, 2009, St. Asaph, United Kingdom 


\title{
OPTICS OUTREACH IN IRISH CONTEXT
}

\author{
Emer Mc Hugh and Arlene Smith \\ Applied Optics Group \\ School of Physics \\ National University of Ireland Galway, Ireland.
}

\begin{abstract}
The Applied Optics Group, National University of Ireland Galway is a research centre involved in programmes that cover a wide variety of topics in applied optics and imaging science, including smart optics, adaptive optics, optical scattering and propagation, and engineering optics. The Group have also developed significant outreach programmes both in Primary and Post-Primary schools. It is recognised that there is a need for innovation in Science Education in Ireland and we are committed to working extensively with schools. The main aim of these outreach programmes is to increase awareness and interest in science with students and enhance the communication skills of the researchers working in the Group. The education outreach team works closely with the relevant teachers in both Primary and PostPrimary schools to design and develop learning initiatives to match the needs of the target group of students. The learning programmes are usually delivered in the participating schools during normal class time by a team of Applied Optics specialists. We are involved in running these programmes in both Primary and Post-Primary schools where the programmes are tailored to the curriculum and concentrating on optics and light. The students may also visit the Groups research centre where presentations and laboratory tours are arranged.

The Applied Optics Group is an active member of TREO - the Third Level Research Education and Outreach Group which coordinates outreach activities nationally and supported by Science Foundation Ireland (SFI).
\end{abstract}




\section{INTRODUCTION}

More so than ever in this economic downturn, Ireland must produce high quality skilled graduates in Science and Technology subjects. According to a recent Irish Government Report ${ }^{1}$ one of the objectives for the future is to make Ireland an innovation and commercialisation hub in Europe, a country that combines the features of an attractive home for innovative Research and Development and a highlyattractive incubation environment for the best entrepreneurs in Europe and beyond. This will be the successful formula for the next phase of the development of the Irish economy and for delivering quality, well-paid jobs.

Research funding through Science Foundation Ireland (SFI), Enterprise Ireland and the Industrial Development Authority (IDA) is to be used to instil a commercialisation culture in third-level institutions alongside the now embedded teaching and research culture. The production of skilled graduates is essential in developing our Third Level Educational System in Ireland not least in the area of Research. Quality research needs to feed into quality teaching and learning at undergraduate level this in turn will ensure that we produce top quality graduates with an interest and capacity to lead future research projects. A lack of Science and Technology graduates has long been recognised in Ireland as a problem and new ways are being devised and implemented to alter this trend. Outreach programmes are one such innovation.

In the case of the Science outreach programmes discussed in this paper they are a new form of supplementary education in Irish schools. They have only been in operation for approximately five to seven years and their primary role is to support teachers in Primary and Post-Primary education in Ireland. These outreach programmes aid science education by raising students' interest and enthusiasm in science and technology.

In order to broaden participation in science and technology subjects in Third Level Education in Ireland outreach programmes have been introduced in these institutions, the programmes help to bring additional knowledge from third level institutions to the different stakeholders such as students, teachers, schools, parents and the general public. Anecdotal evidence suggests that these programmes are accepted in a very positive light by both students and teachers and that they are helping to improve the scientific knowledge and interest of students from Primary, Post-primary and Third level education in Ireland. As Van Esbeck ${ }^{2}$ has stated "scientific research and an educated population are key drivers in the economic progress of a country".

Funding and support at all levels of science education are essential to guarantee Ireland's economic and social health. In a recent Irish Government Report ${ }^{1}$ it was stated that there was a need to restructure our economy so that we can take full advantage of the global recovery when it comes. One way to develop our knowledge economy is by expanding our science and technology base and working on our education policies and practices particularly for science subjects. A strong science base protects economies during a downturn and allows a quicker recovery when global conditions change. 


\section{EDUCATION IN IRELAND}

\subsection{Primary School Science Education (Ages 4-12 years)}

It was not until 2003 that science as a full subject was introduced to Irish Primary schools. One of the main aims of the new Primary School Science Curriculum ${ }^{3}$ is to "enable the child to acquire knowledge, skills and attitudes so as to develop an informed and critical understanding of social, environmental and scientific issues". The curriculum was designed in order that the child would develop as a responsible individual who will contribute and help to maintain our local, regional, national and global communities, caring for the environment with an appreciation of the world and its sustainable resources. These outreach programmes are one way to aid the integration of science subjects in primary schools.

In this curriculum the development of the child's ideas is central to science education and the previously held ideas and beliefs of the child are modified in order to develop more scientific understanding. The teaching format adopted for science takes two forms of understanding: conceptual and procedural. Conceptual is concerned with the development of scientific knowledge and a deepening of fundamental scientific ideas while the use of the scientific process comes under procedural where the child works scientifically and engages in scientific enquiry. Science education is concerned with the knowledge and understanding of the biological and physical aspects of the world but it is important that the learning activities promote curiosity and enjoyment so that the pupils develop a lasting interest in science.

\subsection{Post-Primary School Science Education (Ages 12-18 years)}

The follow on programme from the Primary school curriculum is the Junior Certificate course. In PostPrimary education in Ireland this section of the course targets students from first year to third year usually in the age range of 12-15 years who, at the end of their third year, sit their first formal state exam. The 2003 Junior Certificate revised science syllabus ${ }^{4}$ was drawn up to cater for a whole range of students whose ability, aptitude and achievements may differ. It was designed to further develop the knowledge, understanding, skills and competencies acquired at Primary level. The curriculum is more activity based than the previous curriculum and is designed to build on the experiences students have had at Primary level. The development of scientific literacy skills, further builds on an appreciation of the impact that science has on our lives and environment.

The rationale of this new curriculum is that:

In an era of rapid scientific and technological change the study of science is fundamental to the development of the confidence required to deal with the opportunities and challenges that such change presents in a wide variety of personal and social contexts ${ }^{4}$.

It is hoped that many students will be encouraged to study science subjects in the senior cycle as a result of this more hands on practical syllabus and even go so far as to conduct further studies or work in this area.

As a follow on from the Junior Certificate course, the Leaving Certificate Programme aims to provide continuity with and progression from the Junior Certificate programme. The emphasis is placed on preparing students for the requirements needed for further education or training. The Leaving Certificate science syllabus is designed to incorporate the principles, procedures and concepts of the subject, it is 
also designed to take into account its interface with technology and social, political and the economic issues of the day. As the introduction to the Physics Science Syllabus ${ }^{5}$ in the Leaving Certificate states "science education in the senior cycle should reflect the changing needs of students and the growing significance of science for strategic development in Ireland.

\section{OUTREACH PROGRAMMES FORMAT}

Following is an outline of the delivery methods used and some of the hands-on experiments conducted with the students.

\section{Format I - Primary School Programmes}

The aim of these programmes is to further develop the student's knowledge of science in terms of understanding, attitudes, skills, competencies and to deepen and extend their educational experiences. These programmes aid the development of the student's personal and social skills preparing them for further study in science and supporting their transition from primary to post-primary education.

The outreach programmes usually take place in the students own classrooms in their Primary School and to date we have concentrated on the age range of $10-12$ year olds. The class sizes average twenty five to thirty students with one teacher in attendance; we in turn provide a minimum of three researchers together with the outreach officer. The researchers may be either post-graduate students or post-doctoral level. The programmes comprise one visit to the school for four consecutive weeks and the duration of the class varies from sixty to ninety minutes. The format follows a pre-agreed programme, where a general introduction to the subject is given and then the students are divided into four to five groups of four-six, with each group having a researcher working with them on the specific experiment. Studying the interaction and dynamics of the children in the groups gives us an indication of their performance and the learning achieved.

Some of the subjects covered included Eye Dominance, investigation of the Blind Spot, the Visible Spectrum, Colour Vision, Rainbows, and experiments with White Light, explaining properties of light, use of mirrors, imaging and an examination of Telescopes and Microscopes. The use of discharged used disposable cameras proved most effective in comparing the similarity of the properties of the eye and the camera as the students work on their own individual cameras for this experiment.

\section{Format II - Primary School Programmes}

These students visit the University campus where an introduction to our Research Group is arranged together with presentations and visits to our various laboratories. This format gives us access to a wider audience as we can cater for larger numbers and where the researchers are available in their laboratories to give a more comprehensive view of their research. We hope to develop these school visits and will plan future programmes with a view to expanding our target population. 


\section{Format I - Post-Primary Schools Programmes}

These programmes are mainly conducted on the University campus and follow a similar format to the primary school campus visits with an introduction to the Research Group followed by laboratory tours. There is a core group of research outreach officers from science research centres within NUI Galway campus who work together to run these programmes and help target relevant schools.

The students are mainly from Transition Year or fifth year. They are in the 14-16 age group. Transition year is a form of gap year, optional in some schools, which students take after the Junior Certificate exam. There are often a couple of core subjects studied during the year while the students get the opportunity to try out subjects not previously studied. At the beginning of fifth year, students choose the subjects they will study for their Leaving Certificate exam (this is equivalent to A-Levels in the United Kingdom and the Baccalaureate in Europe). One of the advantages of these tours is that students can familiarise themselves with the University campus and the research work being carried out. They can relate their subject choices for their Leaving Certificate exams to University courses and careers in science research.

\section{Format II - Post-Primary Schools Programmes}

As part of an ongoing developmental policy we have devised a programme incorporating an element of the new revised curriculum in collaboration with some post-primary science teachers. This programme is delivered to second year students, thereby aiding the teachers in their work and giving the students an insight into the scientific world that they may not have had previously. This programme proved very successful but mainly we have found that due to the vast range of subjects each student must cover there is a limit to the access we have to teachers and students. We have also participated in some Transition Year programmes on site covering areas of mutual interest in the area of Physics.

\section{SAMPLE PROJECTS PRESENTED}

\subsection{Primary schools}

As outlined in Section 3, one of the programmes we run with primary school students involves a series of sixty to ninety minute visits to the primary school over a four week period. The programme is delivered in the classroom, starting with an introduction to the material to be covered that week and then moving to smaller groups with a more hands-on approach. Here we will outline two areas covered in these programmes.

\subsubsection{Parts of the eye}

This project involves introducing the students to the anatomy of the eye including the function of each part. After an initial introduction is given by the outreach team, the students are encouraged to identify the parts of the eye on their own handout by completing the labels on a diagram of the eye. When the outreach team returns to the school the following week, this study is continued. We explain the similarity between the parts of the eye and the parts of a simple point-and-shoot camera. Each student is given a used disposable camera with the film removed and the internal capacitance discharged for safety (to avoid an electric shock!). The students take the camera apart piece by piece, noting the function of each 
component, and then reassemble it. In this way, the students get hands-on experience of a compact imaging system.

\subsubsection{Eye dominance}

In this project, students are introduced to the concept of a dominant eye and investigate whether it relates to left or right handedness. The students are asked to extend one arm and form a small circular opening with the thumb and index finger, then with both eyes open view a distant object through the opening. The students then alternate closing the left and right eyes. When the object being viewed stays in the same position as with both eyes open, the eye open is the dominant eye. When the object shifts from view, the open eye is non-dominant. In this lesson, students are introduced to the concept of correlation, though it is presented in a fun, informal way: if you are right-handed, are you also right-eyed? (The answer is "no, not necessarily".)

\subsubsection{Blind Spot}

In this exercise, students learn about the internal anatomy of the eye and the location of the 'blind spot'. At the back of the eye, at the location of the optic nerve, there is a region with no photoreceptors (lightsensitive cells). If an image falls on this region, it will not be seen. This is the blind spot. The students are given a sheet of paper with a black cross on the left and a red circle on the right. Starting with the paper held close to the face, the students close their left eye and look at the cross with their right eye. As the paper is moved away from the face, the red circle disappears from their peripheral vision, only to reappear as the sheet is moved further away. The distances from the eye where the spot disappears and reappears are then used to calculate the size of the blind spot (or the diameter of the optic nerve).

\subsection{Post-Primary schools}

One programme we have developed for Post-Primary school students comprises the Junior Certificate curriculum on Light. It is run over a three week period for one class per week of one hour and fifteen minutes duration. The main aim of the programme is that at the end of the three week module the students can confidently undertake their state exam in the area of Light. Topics covered include dispersion (illustrated using a simple prism and a torch/light box), reflection (angle of reflection investigated using a plane mirror; two plane mirrors and a carboard tube used to construct a simple periscope) and refraction (bringing an image to focus using a convex lens). The outreach team present the programme in a similar way to the Primary school format, where following an introduction to the topic, the students are encouraged to investigate set problems in a hands-on way. Each week, the outreach team assess progress with the teacher and the programme concludes with a written test at the end of the third week.

\section{CONCLUSION}

Our outreach programmes at both Primary and Post-Primary schools level have been outlined. They range from a three to four week programme delivered in the classroom to organised campus tours of science research centres. Thus far these programmes have been well received; they tie in with the newly introduced curriculum in Primary and Post-Primary schools and offer an alternative approach to classroom learning. The outreach team present the material in an enthusiastic and hands-on way. The Primary School programmes form part of the child's initial introduction to science and the Post-Primary school programmes provide that vital contact between the students and the University research environment linking their school work with real career choices. 


\section{ACKNOWLEDGEMENTS}

This research was supported by Science Foundation Ireland under Grant No. SFI/07/IN.1/I906

\section{REFERENCES}

[1] Department of the Taoiseach (2008) "Building Ireland's Smart Economy A Framework for Sustainable Economic Renewal 2009-2014", Stationery Office: Irish Government Publications.

[2] Van Esbeck G (2003) Editorial The Irish Scientist Dublin Oldbury Publishing.

[3] Department of Education and Science (1999a) "Primary school curriculum science". Stationery Office: Irish Government Publications.

[4] Department of Education and Science (2003) "Junior certificate science syllabus (ordinary and higher level)". Stationery Office: Irish Government Publications.

[5] Department of Education and Science (1999) Physics syllabus (ordinary level and higher level) Dublin: Stationery Office 